\title{
A Think-Aloud Study of Function-to-Form Mapping in Modal Use: Based on the Concept-Oriented Approach
}

\author{
Lai Peng \\ School of Foreign Languages, Sun Yat-sen University, Guangzhou, China
}

Email address:

flslp@mail.sysu.edu.cn

To cite this article:

Lai Peng. A Think-Aloud Study of Function-to-Form Mapping in Modal Use: Based on the Concept-Oriented Approach. International Journal of Applied Linguistics and Translation. Vol. 7, No. 3, 2021, pp. 87-95. doi: 10.11648/j.ijalt.20210703.12

Received: August 8, 2021; Accepted: August 21, 2021; Published: August 31, 2021

\begin{abstract}
Due to the complexity of Chinese modal system in terms of function-form relation, misuse of Chinese modal verbs is quite common among learners of Chinese from other countries. Based on the concept-oriented approach, this paper aims to investigate how learners of Chinese as a foreign language choose modal forms to express the concept of modality in terms of function-to-form mapping, so as to shed light on the teaching of modal use. Modal forms investigated in this study are five Chinese modal verbs whose functions are categorized into three conceptual domains: the Speech Act Domain, the Event Domain and the Epistemic Domain. Six learners of Chinese from Poland were recruited to participate in a modal test which comprised of 24 pairs of modal sentences in English and Chinese. They were asked to think aloud while they chose Chinese modal verbs to match the functions expressed by the English modal verbs. Based on the think-aloud data, it is found that in all the three conceptual domains participants have perceived ambiguities between modal verbs which express similar functions, especially in the Epistemic Domain. Competition between these modal verbs arose in their mind where ambiguity was perceived in the process of function-to-form mapping. Qualitative analyses of the think-aloud data revealed that Epistemic Domain is the most difficult domain for the participants in terms of function-to-form mapping, and "Hui/Neng" is the most confusing pair of Chinese modal verbs which may require more explicit instruction. Apart from studying the cognitive processing of modal forms and the cognitive ambiguity between them, this think-aloud case study also manifested the influence of social context on second language acquisition. It carries pedagogical implications for modal acquisition and indicates a socio-cognitive perspective for future studies on modality.
\end{abstract}

Keywords: Conceptual Domains, Chinese Modal Verbs, Function-to-Form Mapping, Ambiguity, Concept-Oriented Approach, Second Language Acquisition

\section{Introduction}

Based on Sweetser [1], Shen distinguished three conceptual domains in terms of Chinese words/sentences: the domain of uttering (言域), the domain of acting (行域) and the domain of knowing (知域) [2]. He pointed out that the use of modal verbs can most clearly illustrate the three conceptual domains. Modal verbs used in utterances to express request, permission, suggestion and so on entail specific speech acts, so they belong to the domain of uttering, also known as "Speech Act Domain" [1]; modal verbs that express ability, volition, duties or obligations entail actions/events, so they belong to the domain of acting (in this paper, it will be referred to as the Event Domain); modal verbs that express inference/judgment based on the speaker's knowledge belong to the domain of knowing, also known as "Epistemic Domain" [1]. Although Shen used a Chinese modal verb “能” (Neng) as an example to introduce the three domains, his study focused on investigation of the three domains of compound sentences instead of modal verbs [2].

This paper intends to focus on the three domains of modal verbs and study the modal use in terms of function-to-form mapping. The concept-oriented approach is adopted for this purpose. The concept-oriented approach investigates the linguistic means/devices that learners use to express a given concept (or subsets of the concept) [3]. "Concepts like time, space or modality can be made the main construct for study" [3]. Previous studies using this approach have investigated the acquisition and use of linguistic forms to express concepts related to time and space etc. But the concept of modality has 
not been investigated adequately from the concept-oriented perspective.

Modality as a concept covers all the three of the above-mentioned conceptual domains. Due to the polysemous feature of Chinese modal verbs, the same modal verb can express modal meanings in different conceptual domains, depending on the context. The three conceptual domains of modal verbs will be deemed in this paper as the subsets of the concept of modality. As a concept, modality can be expressed by a variety of means/devices, but in this paper only modality expressed by modal verbs is under investigation.

This study is based on integration of the conceptual domains and the concept-oriented approach. It aims to investigate how the subsets of modality are expressed by learners and how to cognitively account for learners' performance in function-to-form mapping. It is hoped that this will shed light on modal acquisition.

\section{The Concept-Oriented Approach}

Concept-oriented approach is one of the functionalist approaches to Second Language Acquisition (SLA). According to functionalists, research emphasis should be put on meaning/function and how it is expressed by linguistic forms [3]. Concept-oriented approach identifies one concept/meaning and focuses on the function-to-form mapping in learners' use of language [3]. As adult learners have already acquired the underlying concepts from their mother tongue, what they need to acquire in the target language is specific ways or means to express those concepts [3], i.e., what they need to learn is the linguistic forms that match the functions. The influence of meaning/function on the choice of forms is the central issue for research under the concept-oriented approach.

Studies of learner production from the concept-oriented perspective do not only investigate function-to-form mapping, but also try to observe how the balance between the forms for expressing the given concept/function changes over time [3]. For functionalists, language acquisition is the process of reorganizing the balance among different means of expression for a certain concept [3]. Balancing of the competitive strength of different forms for expressing the same meaning/concept is also the focus of studies which are based on the Competition Model. As one of the functionalist approaches, the Competition Model studies the processing and weighing of linguistic forms [3]. It holds the view that any one form may realize several functions and any one function can be expressed through several forms [4]. For forms which can express the same function, competition between them arises in the learners' mind during the process of function-to-form mapping.

Based on the concept-oriented approach and related functional perspectives in terms of competition, this paper aims to study how learners of Chinese choose linguistic forms to express the concept of modality and to observe the competition of different forms in the participants' mind when they process a modal task.

\section{Methods}

\subsection{Participants}

The data for this study came from 6 participants who are adult learners of Chinese from Poland, who all have Polish as their mother tongue. In addition to Polish and Chinese, they can all speak English (as an international language). They are at different levels of Chinese proficiency, measured by the HSK test (a language test of Chinese proficiency) that they have taken in China. Participants' anonymity is maintained in this study and for reference to them in this paper they are numbered from 1 to 6 : participant 1 will later be referred to as $\mathrm{P} 1$, participant 2 will be referred to as $\mathrm{P} 2$, and so on. $\mathrm{P} 1$ has passed HSK 5, P2, P3 \& $\mathrm{P} 4$ have passed HSK 4, P5 has passed HSK 3 and P6 has passed HSK 2 (which is a lower level of Chinese proficiency). They were all studying or working in China at the time of participating in this study.

\subsection{Instruments}

Think-aloud protocol was used in order to obtain evidence of language processing in terms of modal use. Instructions in Guo about how to carry out a think-aloud study [5] were followed. This think-aloud study investigates how the participants process the modal task in terms of function-to-form mapping. Participants were allowed to speak either English or Chinese when they tried to describe their thinking process.

The modal task comprises 24 pairs of modal sentences, among which the English sentences are taken from the conversations in a British TV play named "Downton Abbey", and the Chinese ones are the translated sentences of the English ones as shown on the screen of this TV play. Screenshots of the 24 pairs of sentences are used for the modal task. In each of the Chinese sentences, the modal verb is replaced by a blank which the participants need to fill in with a Chinese modal verb. Five modal verbs in Chinese are provided for participants to choose from. They need to make the choice according to the meaning expressed by the modal verb in the corresponding English sentence. In other words, they need to express the concept of modality encoded by the English modal verb with an equivalent Chinese modal verb. The modal meanings in these 24 pairs of sentences can be categorized in the above-mentioned three conceptual domains, with 8 pairs in each domain.

The sentences for the modal task were taken from the conversations in a TV play in consideration of both the functionalist view that language used communicatively should be taken as evidence and the concept-oriented perspective that tasks should be designed in a way which facilitates the investigation of form-meaning association [3]. In the modal task for the present study, the English sentences are the ones used in communication and they provide meaning constraints on the participants' choice of Chinese modal forms. Participants need to describe their thinking process while they choose Chinese modal verbs to express the meaning of the corresponding English modal verb. 
The think-aloud task was done through Tencent WeMeet App, with one participant joining in at a time. The participants could see on the screen each pair of the sentences (i.e., Sentence 1-Sentence 24) one by one as they went through the whole task. The modal verbs/forms listed for choice in Sentence 1-15 are the following five: “会”, “要”, “能”, “可以” and “应该”; the modal forms for choice in Sentence 16-20 are the five modal verbs in their negative forms: “不会”, “不要”, “不能”, “不可以” and “不应该”; the modal forms for choice in Sentence 21-24 are the five modal verbs in their interrogative forms: “会不会”, “要不要”, “能不能”, “可不可 以” and “应不应该”. The involved English modal verbs in the corresponding English sentences are "can/could, may/might, will/would, shall/should". For each pair of modal sentences, participants need to choose from the given five Chinese modal forms to fill in the blank of the Chinese sentence. They made their choice and described their thinking process orally while they went through Sentence 1 to Sentence 24 one by one.
This think-aloud modal task took about one hour for each participant. Their processing of the 24 modal sentences in terms of function-to-form mapping is recorded, later transcribed and analyzed to see how meanings related to modality are expressed and how competition works when there are two or more modal forms which can express the same function.

\section{Results}

The think-aloud data were analyzed qualitatively in terms of the expression of modality and the processing of modal forms. The results are shown in Table 1 as to how many of the 6 participants have chosen the most appropriate modal form to fill in the blank of each Chinese sentence. The 24 pairs of sentences are categorized into three conceptual domains according to the meaning of the modal forms in both the Chinese and the English sentence.

Table 1. Number of participants who have chosen the most appropriate modal form for each sentence.

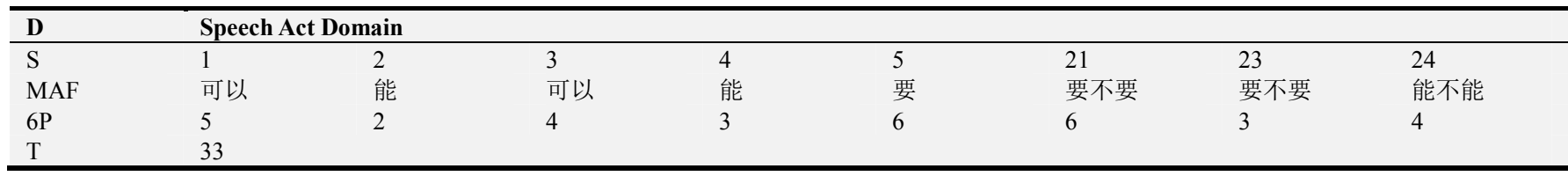

\begin{tabular}{|c|c|c|c|c|c|c|c|c|}
\hline $\bar{D}$ & $\overline{E v}$ & & & & & & & \\
\hline$S$ & 6 & 7 & 8 & 9 & 10 & 16 & 17 & 19 \\
\hline MAF & 能 & 可以 & 能 & 会 & 应该 & 不能 & 不能 & 不能 \\
\hline $6 \mathrm{P}$ & 2 & 5 & 5 & 4 & 6 & 3 & 2 & 1 \\
\hline
\end{tabular}

\begin{tabular}{|c|c|c|c|c|c|c|c|c|}
\hline D & Epi & & & & & & & \\
\hline $\mathrm{S}$ & 11 & 12 & 13 & 14 & 15 & 18 & 20 & 22 \\
\hline MAF & 能 & 会 & 能 & 会 & 应该 & 不会 & 不会 & 能不能 \\
\hline $6 \mathrm{P}$ & 0 & 3 & 3 & 4 & 6 & 5 & 4 & 2 \\
\hline $\mathrm{T}$ & 27 & & & & & & & \\
\hline
\end{tabular}

Notes for Table 1: D stands for domain, $\mathrm{S}$ for sentence, MAF for the most appropriate form, $\mathrm{P}$ for participants, T for the total of the most appropriate choices made by the participants in each domain.

In the modal task for this think-aloud study, the focus is on the mapping process between the specified function and the chosen form, not on the correctness of the choice, hence the chosen forms by the participants are evaluated according to whether it is the most appropriate modal form in relation to the intended meaning/function, as there might be two or more forms which are syntactically acceptable for the blank of the given Chinese sentence. Participants need to choose the one which is closest in meaning to the modal verb in the original English sentence.

\subsection{Analysis of Function-to-Form Mapping in the Conceptual Domains of Modality}

From Table 1, it can be seen that “能” (Neng) as the most appropriate modal verb for Sentence 2, 4, 6, 11 and 13 was chosen by fewer participants (compared with the number of participants who made appropriate choices in the use of modal verbs for other sentences), so was its negative form “不能” (Bu Neng) in Sentence 16, 17, 19 and its interrogative form
“能不能” (Neng Bu Neng) in Sentence 22. This shows that fewer participants mapped the modal forms “能/不能/能不能” to the modal meanings expressed by the corresponding English sentences, i.e., modal forms “能/不能/能不能” were not used where they should have been used. It can be inferred that participants have not got very good command of “能” (and its related forms), therefore it was less used by them. “能” as a modal verb in Chinese has as many as 5 meanings: ability, condition, permission, inference and volition [6]. However, most of the participants tended to map "能” only with the meaning of "ability" (能力). As none of the above sentences $[2,4,6,11,13,16,17,19,22]$ is associated with "ability", the participants were not aware that “能 " or its negative/interrogative form is the most appropriate choice for the blank in these particular sentences. The modal meanings in the above-mentioned sentences are respectively related to $\operatorname{permission}_{(\mathrm{S} 2, \mathrm{~S} 16, \mathrm{~S} 17, \mathrm{~S} 19)}$, $\operatorname{volition}_{(\mathrm{S} 4, \mathrm{~S} 6)}$, and inference ${ }_{(\mathrm{S} 11, \mathrm{~S} 13 \text {, }}$ $\mathrm{S} 22)$. That might be the reason why the participants did not choose “能” for these sentences. But in Sentence 8 "I can't get 
there more than twice/我每周最多也就_去两次”, 5 out of the 6 participants chose “能” for the blank and in this context "能" is indeed the most appropriate modal verb. But according to their think-aloud recording it is found that most of them chose “能” for Sentence 8 because they perceived the modal meaning in this sentence as being related to "ability" (能力), so they matched it with “能”, though actually in this sentence the modal meaning is a combination of "ability" and "permission", a kind of semantic phenomenon known as "merger" [7].

Apart from mapping “能” with "ability", according to the think-aloud recording, most participants tended to match “会” with "will" to show futurity, match "要” with "want to" to show inclination/determination, and match “应该” with “should" to mean obligation. As “会”, “要” and “应该” has fewer meanings than “能” (i.e., each of them has three meanings while “能” has five), the participants seemed to have better command of “会”, “要” and “应该” (which can be seen in Table 1), as "futurity" is indeed the most typical meaning of “会”, “inclination/determination" is the most typical meaning of “要”, and "obligation” is the most typical meaning of “应该”. This kind of one-to-one correspondence by the participants in terms of function-to-form mapping sometimes does enable them to make appropriate choices in modal use, but sometimes things might be different. For example, in Sentence 22 "we can't know if Matthew will come through it/我们不知道马修_活下来”, as the English modal is "will" (in a "if" clause), most participants mapped it with the interrogative form of “会” (i.e., 会不会), because they thought that "will" shows futurity which is best expressed by “会”. However, in this "if" clause and in this context, using “会不会” is not the most appropriate, and the most appropriate choice for this blank is the interrogative form of “能” (i.e., 能不能) (to show epistemic possibility). Only two participants chose 能不能 for this blank, and one of them said in the think-aloud process: “I think it is “能不能”, because it is not associated with 'will' in the clause but associated with 'can't' in the main sentence". The reasoning in this thinking process by the participant may not be sound enough, but it is thought-provoking to the researcher in terms of how this participant processed the modal verbs in this sentence, and it happened to help this participant make the appropriate choice in terms of function-to-form mapping.

According to the concept-oriented view, the development of function-to-form mapping follows two principles: one-to-one principle and multifunctionality principle [3]. As their proficiency increases, learners may move from the initial stage characterized by one-to-one mapping to a stage characterized by multifunctionality [3]. For example, as mentioned above, participants are found to show one-to-one association of “能” with “ability”, “会” with “will”, “要” with "want to" and “应该” with "should", i.e., they sometimes tend to select the first meaning-to-form mappings according to their stereotyped understanding of the one-to-one correspondence between languages. But participants at higher levels of proficiency may be able to use the same modal verb for different meanings according to the context. For example, P3 who has passed HSK 4 has got very strong awareness of the context. In the think-aloud recording, he mentioned the word "context" when he was processing Sentence 2, 3, 6, 9, 16 , $18,19,20$ and 24. He made choices of Chinese modal verbs according to the context provided by the corresponding English sentences. In Table 2, it can be seen that P3 can use the same modal verb across different functional/conceptual domains: for example, N/BN/NBN (能/不能/能不能) in all the three domains, Ky (可以) in both the Speech Act Domain and the Event Domain, Yg (应该) in both the Event Domain and the Epistemic Domain. This shows he has got good understanding of the polysemous feature of Chinese modal verbs and their use in different contexts.

Table 2. The most appropriate modal form for each sentence and the ones used by the participants.

\begin{tabular}{|c|c|c|c|}
\hline & Speech Act Domain & Event Domain & Epistemic Domain \\
\hline MAF & $\begin{array}{l}\mathrm{Ky}_{(\mathrm{S} 1)}, \mathrm{N}_{(\mathrm{S} 2)}, \mathrm{Ky}_{(\mathrm{S} 3)}, \mathrm{N}_{(\mathrm{S} 4)}, \mathrm{Y}_{(\mathrm{S} 5)}, \mathrm{YBY}_{(\mathrm{S} 21)}, \mathrm{YBY}_{(\mathrm{S} 23)}, \\
\mathrm{NBN}_{(\mathrm{S} 24)}\end{array}$ & $\begin{array}{l}\mathrm{N}_{(\mathrm{S} 6)}, \mathrm{Ky}_{(\mathrm{S} 7)}, \mathrm{N}_{(\mathrm{S} 8)}, \mathrm{H}_{(\mathrm{S} 9)}, \mathrm{Yg}_{(\mathrm{S} 10)} \\
\mathrm{BN}_{(\mathrm{S} 16)}, \mathrm{BN}_{(\mathrm{S} 17)}, \mathrm{BN}_{(\mathrm{S} 19)}\end{array}$ & $\begin{array}{l}\mathrm{N}_{(\mathrm{S} 11)}, \mathrm{H}_{(\mathrm{S} 12)}, \mathrm{N}_{(\mathrm{S} 13)}, \mathrm{H}_{(\mathrm{S} 14)}, \mathrm{Yg}_{(\mathrm{S} 15)}, \mathrm{BH}_{(\mathrm{S} 18)}, \\
\mathrm{BH}_{(\mathrm{S} 20)} \mathrm{NBN}_{(\mathrm{S} 22)}\end{array}$ \\
\hline P1 & $\mathrm{Ky}_{(\mathrm{S} 1)}, \mathrm{Ky}_{(\mathrm{S} 3)}, \mathrm{Y}_{(\mathrm{S} 5)}, \mathrm{YBY}_{(\mathrm{S} 21)}, \mathrm{NBN}_{(\mathrm{S} 24)}$ & $\mathrm{Ky}_{(\mathrm{S} 7)}, \mathrm{N}_{(\mathrm{S} 8)}, \mathrm{H}_{(\mathrm{S} 9)}, \mathrm{Yg}_{(\mathrm{S} 10)}$ & $\mathrm{H}_{(\mathrm{S} 12)}, \mathrm{N}_{(\mathrm{S} 13)}, \mathrm{H}_{(\mathrm{S} 14)}, \mathrm{Yg}_{(\mathrm{S} 15)}, \mathrm{BH}_{(\mathrm{S} 18)}, \mathrm{BH}_{(\mathrm{S} 20)}$ \\
\hline $\mathrm{P} 2$ & $\begin{array}{l}\mathrm{Ky}_{(\mathrm{S} 1)}, \mathrm{N}_{(\mathrm{S} 2)}, \mathrm{Ky}_{(\mathrm{S} 3)}, \mathrm{N}_{(\mathrm{S} 4)}, \mathrm{Y}_{(\mathrm{S} 5)}, \mathrm{YBY}_{(\mathrm{S} 21)}, \mathrm{YBY}_{(\mathrm{S} 23)}, \\
\mathrm{NBN}_{(\mathrm{S} 24)}\end{array}$ & $\mathrm{Ky}_{(\mathrm{S} 7)}, \mathrm{N}_{(\mathrm{S} 8)}, \mathrm{H}_{(\mathrm{S} 9)}, \mathrm{Yg}_{(\mathrm{S} 10)}, \mathrm{BN}_{(\mathrm{S} 16)}$ & $\mathrm{H}_{(\mathrm{S} 12)}, \mathrm{H}_{(\mathrm{S} 14)}, \mathrm{Yg}_{(\mathrm{S} 15)}, \mathrm{BH}_{(\mathrm{S} 18)}, \mathrm{BH}_{(\mathrm{S} 20)}$ \\
\hline P3 & $\mathrm{Ky}_{(\mathrm{S} 1)}, \mathrm{Ky}_{(\mathrm{S} 3)}, \mathrm{N}_{(\mathrm{S} 4)}, \mathrm{Y}_{(\mathrm{S} 5)}, \mathrm{YBY}_{(\mathrm{S} 21)}, \mathrm{YBY}_{(\mathrm{S} 23)}, \mathrm{NBN}_{(\mathrm{S} 24)}$ & $\mathrm{Ky}_{(\mathrm{S} 7)}, \mathrm{Yg}_{(\mathrm{S} 10)}, \mathrm{BN}_{(\mathrm{S} 16)}$ & $\mathrm{N}_{(\mathrm{S} 13)}, \mathrm{Yg}_{(\mathrm{S} 15)}, \mathrm{BH}_{(\mathrm{S} 18)}, \mathrm{BH}_{(\mathrm{S} 20)}$ \\
\hline P4 & $\mathrm{Ky}_{(\mathrm{S} 1)}, \mathrm{N}_{(\mathrm{S} 2)}, \mathrm{Ky}_{(\mathrm{S} 3)}, \mathrm{N}_{(\mathrm{S} 4)}, \mathrm{Y}_{(\mathrm{S} 5)}, \mathrm{YBY}_{(\mathrm{S} 21)}$ & $\begin{array}{l}\mathrm{N}_{(\mathrm{S} 6)}, \mathrm{Ky}_{(\mathrm{S} 7)}, \mathrm{N}_{(\mathrm{S} 8)}, \mathrm{H}_{(\mathrm{S} 9)}, \mathrm{Yg}_{(\mathrm{S} 10)}, \\
\mathrm{BN}_{(\mathrm{S} 16)}, \mathrm{BN}_{(\mathrm{S} 17)}, \mathrm{BN}_{(\mathrm{S} 19)}\end{array}$ & $\mathrm{H}_{(\mathrm{S} 14)}, \mathrm{Yg}_{(\mathrm{S} 15)}, \mathrm{BH}_{(\mathrm{S} 18)}, \mathrm{NBN}_{(\mathrm{S} 22)}$ \\
\hline P5 & $\mathrm{Ky}_{(\mathrm{S} 1)}, \mathrm{Y}_{(\mathrm{S} 5)}, \mathrm{YBY}_{(\mathrm{S} 21)}, \mathrm{YBY}_{(\mathrm{S} 23)}$ & $\mathrm{N}_{(\mathrm{S} 8)}, \mathrm{H}_{(\mathrm{S} 9)}, \mathrm{Yg}_{(\mathrm{S} 10)}$ & $\mathrm{H}_{(\mathrm{S} 12)}, \mathrm{N}_{(\mathrm{S} 13)}, \mathrm{H}_{(\mathrm{S} 14)}, \mathrm{Yg}_{(\mathrm{S} 15)}, \mathrm{BH}_{(\mathrm{S} 18)}, \mathrm{BH}_{(\mathrm{S} 20)}$ \\
\hline P6 & $\mathrm{Y}_{(\mathrm{S} 5)}, \mathrm{YBY}_{(\mathrm{S} 21)}, \mathrm{NBN}_{(\mathrm{S} 24)}$ & $\mathrm{N}_{(\mathrm{S} 6)}, \mathrm{Ky}_{(\mathrm{S} 7)}, \mathrm{N}_{(\mathrm{S} 8)}, \mathrm{Yg}_{(\mathrm{S} 10)}, \mathrm{BN}_{(\mathrm{S} 17)}$ & $\mathrm{Yg}_{(\mathrm{S} 15)}, \mathrm{NBN}_{(\mathrm{S} 22)}$ \\
\hline
\end{tabular}

Notes for Table 2: S stands for sentence, and the number which follows " $\mathrm{S}$ " indicates the sentence number where the modal form is used; MAF stands for the most appropriate form; P stands for participant; H stands for modal form “会” (Hui), Y for “要” (Yao), N for “能” (Neng), Ky for “可以” (Keyi), Yg for “应该” (Yinggai); B for the negative marker “不” (Bu). These abbreviations are used mainly in the tables for the purpose of conciseness.

The use of the multifunctionality principle can also be observed in other participants, as shown in Table 2. The row named "MAF" in this table presents the most appropriate modal form for each sentence in the conceptual domains ( 8 in each domain). Each of the following rows shows the most appropriate modal forms used by the participants. It can be seen that some of the same forms were used by each participant across different domains, which is a manifestation of the multifunctionality principle being used by each participant. But P6 showed less use of the same modal verb across different domains, which indicates this participant had less understanding of the multifunctionality principle. As is shown in Table 2, P6 used only two modal verbs “能” (in its different forms: N, BN \& NBN) and “应该” (Yg) across 
different domains. Other participants who are at a higher proficiency level used more than two modal verbs (and their related forms) across different domains.

Concept as meaning/function is what the participants need to express, and equivalence of meaning is indeed a criterion used by some participants for evaluation of their chosen answers when they matched a form with a given function. For example, in the think-aloud recording of $\mathrm{P} 3$, he said things like: “(Here) “可以' is the closest meaning to 'could'(S3)”, ““要不 要' is the closest to English 'Shall we' (S21)". When he chose modal forms to fill in the Chinese sentences, he looked at the corresponding English sentences as the source of translation so as to ensure the equivalence of meaning in translation. He mentioned the word "translate/translation" when he was processing nineteen sentences among all the 24 . He thought aloud in the following words when he processed some of the modal sentences: "If I chose '会', the translation would be different; This is the closest translation; This is not the literal translation; I can't translate literally; Other modal verbs do not match the translation" etc. Function-to-form mapping based on equivalence of meaning in terms of translation can thus be observed from the think-aloud recording of this participant.

Although one-to-one principle was sometimes followed by some participants at some stage, in some particular contexts they may sense the inappropriateness of this principle. Taking Sentence 19 “Why shouldn't she learn to cook? / 她怎么就 学学做饭了?" as an example, the modal forms for choice are: 不会, 不要, 不能, 不可以, 不应该. Suppose the participants tried to follow the one-to-one meaning-to-form mapping, they would have selected “不应该” to match "shouldn't", as most of them regarded “应该” as the translation of "should". However, most participants could feel the inappropriateness of “不应该” in Sentence 19. For example, P2 said in his think-aloud process: "I can't put 'shouldn't' as “不应该”, ” P3 said: “When seeing the Chinese sentence, “不应该' does not fit in this context”; P4 said: ““不 应该” does not work”; P5 said: “Definitely not “不应该”, because the meaning is different." It can be seen that they realized the infeasibility of one-to-one correspondence in this particular context. But which is the most appropriate modal form in the Chinese sentence of Sentence 19? Most of them felt baffled at the rest of the modal choices. This will lead us to an analysis of ambiguities between modal forms.

\subsection{Analysis of Ambiguities in the Conceptual Domains of Modality}

For Sentence 19 mentioned above, P1 said in the think-aloud process: "Seeing 'should', “应该' immediately came to my mind." But he felt that using “不应该” in the given Chinese sentence to match "shouldn't" was not proper. He then tried some of the other modal choices and put them in the blank one by one, feeling that “不会” did not fit, but he was unable to decide between “不要”, “不能” and “不可以”. He then said: “要简单的想法我就用“不应该”，但是思考思 考就会困惑(Without thinking I would have used “不应该”, but when I think more about it I felt confused)". And he failed to make a final choice for this sentence. This kind of failure was also found in other participants when they tried to match forms with functions. Due to learners' uncertainty in the perception of modal meanings, they might feel there are more than one modal form which can be mapped to a concept (function/meaning). Unsure which one is the appropriate one, they may experience a feeling of ambiguity. For example, when processing the above-mentioned Sentence 19, P3 thought aloud: “' 'shouldn't' means “不应该', but it doesn't fit in this context. I would rather use “不能'. I wouldn't translate literally from English. Which one then? ‘不能”, “不会” or “不 可以’? (Anyway) I shouldn't translate literally.” P6 thought aloud in these words: “I'm thinking between “不可以' or “不 应该'. It's confusing, because 'should' means '应该', but it doesn't fit." According to the illustration of ambiguity by Ely [8], feeling unsure/uncertain or confused is the typical experience of linguistic ambiguities.

Table 3. Ambiguities perceived by the 6 participants in the three domains of modality.

\begin{tabular}{|c|c|c|c|}
\hline & Ambiguities in Speech Act Domain & Ambiguities in Event Domain & Ambiguities in Epistemic Domain \\
\hline P1 & 能/可以 $(\mathrm{S} 2) ;$ 会不会/能不能(S24) & 不要/不能/不可以 ${ }_{(\mathrm{S} 19)}$ & 会/能(S12); 能/可以 ${ }_{(\mathrm{S} 13)}$ \\
\hline $\mathrm{P} 2$ & 能/可以 ${ }_{(\mathrm{S} 2)}$ & 会/能/可以 $(\mathrm{S} 6) ;$ 不能/不可以 ${ }_{(\mathrm{S} 17)}$ & $\begin{array}{l}\text { 能/可以 }{ }_{(\mathrm{S} 11)} ; \text { 会/能 }{ }_{(\mathrm{S} 12)} ; \text { 能/可以 }{ }_{(\mathrm{S} 13)} ; \text { 会/要 }{ }_{(\mathrm{S} 14)} \\
\text { 不会/不要 }{ }_{(\mathrm{S} 18)} \text {; 不会/不要 }(\mathrm{S} 19) ; \text { 会不会/能不能 }{ }_{(\mathrm{S} 22)}\end{array}$ \\
\hline P3 & 要/可以 $(\mathrm{S} 2) ;$ 能不能/可不可以 $(\mathrm{S} 24)$ & $\begin{array}{l}\text { 能/可以 }_{(\mathrm{S} 6)} ; \text { 会/能 }_{(\mathrm{S} 8)} ; \text { 能/可以 }_{(\mathrm{S} 9) ;} \\
\text { 不会/不能/不可以 }_{(\mathrm{S} 19)}\end{array}$ & $\begin{array}{l}\text { 会/能 }(\mathrm{S} 12) ; \text { 能/可以 }{ }_{(\mathrm{S} 11)} ; \text { 会/能 }{ }_{(\mathrm{S} 14)} ; \\
\text { 不会/不能/不可以 }{ }_{(\mathrm{S} 20)} \text {; 会不会/能不能/可不可以 }{ }_{(\mathrm{S} 22)}\end{array}$ \\
\hline P4 & & 会/能 ${ }_{(\mathrm{S} 8)} ;$ 不会/不能 ${ }_{(\mathrm{S} 17)}$ & 不会/不能(S20) \\
\hline P5 & 会/可以 $(\mathrm{S} 3)$ & & 会/能 $(\mathrm{S} 12) ;$ 会/能 $(\mathrm{S} 13)$ \\
\hline P6 & 能/可以 ${ }_{(\mathrm{S} 1)}$; 会/要 $(\mathrm{S} 2) ;$ 要/能 $(\mathrm{S} 3)$ & 不能/不可以 ${ }_{(\mathrm{S} 16)}$; 不可以/不应该(S19) & 会/能 ${ }_{(\mathrm{S} 12)} ;$ 会/能 $(\mathrm{S} 13)$; 不会/不要(S18) \\
\hline
\end{tabular}

Notes for Table 3: S stands for sentence, the number which follows "S" indicates the sentence number where the pair of confusing modal verbs (modal verb A/ modal verb B) is reported by the participants.

In the think-aloud process about the 24 sentences, the uncertainty between choices of modal forms reported by the participants can be seen from Table 3. Pairs and pairs of confusing modal verbs reported by the participants are listed in this table. Based on Table 3, Table 4 is made to show the frequency of each pair of confusing modal verbs reported by the participants. 
Table 4. Frequency of some pairs of confusing modal verbs reported by the 6 participants.

\begin{tabular}{llll}
\hline Pairs of confusing modal verbs & Speech Act Domain & Event Domain & Epistemic Domain \\
\hline 会/能 (\& related forms) & 1 & 3 & 10 \\
能/可以 (\& related forms) & 4 & 4 & 4 \\
会/可以 (\& related forms) & 1 & 0 & 0 \\
会/能/可以 (\& related forms) & 0 & 2 & 2 \\
会/要 (\& related forms) & 0 & 0 & 3 \\
Total & 6 & 9 & 4 \\
\hline
\end{tabular}

From Table 3 and Table 4, it can be seen that the most confusing pair of Chinese modal verbs perceived by the participants is “会/能” (including their related negative and interrogative forms “不会/不能,会不会/能不能”). It was mentioned 14 times in the think-aloud process of the 6 participants, who said they had a problem between 会 and 能 for some of the sentences. The confusion between these two modal verbs was perceived in all the three domains, as both 会 and 能 can mean volition, ability and epistemic possibility. This pair of confusing modal verbs was reported most frequently when participants were processing sentences in the Epistemic Domain, as many as 10 times. This means participants felt the most ambiguities between 会 and 能 when expressing the epistemic function, as both of these two modal verbs are used very often to mean epistemic possibility.

Table 3 and Table 4 show that “能/可以” (including their related negative and interrogative forms “不能/不可以, 能不能/ 可不可以”) is the second most frequently mentioned pair which caused confusion and ambiguity. This pair of modal verbs was mentioned 12 times in the think-aloud process of the 6 participants, making them feel hard to decide which is the most appropriate one for the given sentence. The ambiguity between these two Chinese modal verbs is also perceived in all the three conceptual domains, as both 能 and 可以 can express permission, ability and epistemic possibility. This pair of confusing modal verbs were reported equally often in all the three domains.

Actually, 会, 能 and 可以 are the three modal verbs in Chinese which look very similar in meaning to learners of Chinese, as they can all express ability and epistemic possibility. That is the reason why in Table 3 it can be seen that some participants showed confusion among all these three modal verbs or their related negative and interrogative forms: 不会/不能/不可以,会不会/能不能/可不可以. This shows that pedagogically these three modal verbs may need to be taught in a way that their semantic items and contextual differences can be made more explicit to the learners so as to reduce ambiguity and facilitate differentiation.

From Table 3 and Table 4 it can be seen that participants of this study felt the most ambiguities in the Epistemic Domain, where they reported many pairs of confusing modal verbs. And from Table 1 it is found that participant made the fewest appropriate choices in the Epistemic Domain. This indicates that the expression of epistemic meanings as the subset of modality may need to be emphasized and strengthened in classroom instruction.

\subsection{Analysis of the Competition in Modal Use}

Due to the ambiguity that learners may feel between modal verbs/forms which can express similar functions/meanings, there might be two or more forms which compete with each other in the mind of the learners when they try to match a modal form with a particular modal meaning. They need to weigh and balance those forms during the function-to-form mapping process.

According to the Competition Model (which is also based on the functionalist view), "competition arises from the different devices or cues that signal a particular language function" [9]. For example, according to the results of the present study, there is competition between 会 and 能 in all the three conceptual domains, especially in the domain for expressing the function of epistemic judgment, as shown in Tables 3 and 4, because both of these two modal verbs can be used to signal epistemic function. The participants felt unsure about the differences between them and thus may experience the feeling of ambiguity.

This study finds that where there are the most ambiguities, there might be the most competition. According to Table 1, Table 3 and Table 4, it can be seen that generally the Epistemic Domain is the most difficult domain for the participants in terms of function-to-form mapping, maybe because the expression of epistemic concept/function can be realized by all the five different modal verbs which are the focus of this study. The following two examples from the think-aloud recording provide a glimpse of the weighing and balancing process of different modal forms which compete in the participants' mind when epistemic function is to be expressed.

For Sentence 12 "I thought you would recognize my voice/ 我以为你_听出我的声音”, P5 thought aloud like this: "I feel that two choices fit in this blank: '会' or '能', and I think '会' sounds better (in this sentence). '能' would also work, but it means a little bit differently, because '能' means ability, but '会' means the speaker thought the listener would recognize his/her voice, however the listener didn't. It's not about ability". It can be seen that P5 was evaluating the two competing choices by referring to the meaning: the concept that is to be expressed. According to this participant's description, it shows that “会” was chosen to mean the speaker's judgment (although this participant didn't explicitly express this epistemic idea) and “能” was associated only with the meaning of "ability". Actually “能” can also be used to mean epistemic judgment, but it is often used in different syntactic contexts or to refer to judgment of a different degree of confidence. Anyway, this participant's processing of the competitive weights of the two choices happened to enable $\mathrm{him} /$ her to make the most appropriate choice for Sentence 12: “会”, which outweighs “能” in the process of function-to-form mapping. But some participants may fail to 
adjust the weights of competing choices and may find himself/herself unable to make the final decision. For example, P6 thought aloud about Sentence 12 in the following words: "I think it's either '会' or ‘能'. '要' does not work because it is for things certain or decided. '应该' does not work either. I'm slowly changing my mind towards '能' or '可以'. Because I learn (Chinese) by myself, I base things on similar sentences I have seen or heard. (According to what I have seen or heard) '会' is not so common, ‘要' or “可以’ are more common, and ‘能' sometimes (is common). If I turn off my thinking I would choose ... ? But '会' is ability. Oh, my God!” This participant felt really baffled, and failed to choose a modal form to convey the intended modal meaning in the given sentence. It can be seen that this participant actually hesitated among three choices: 会, 能 and 可以. He/she weighed them according to frequency of their use (whether they are common or not), and finally seemed to want to choose '会', but tended to associate the meaning of '会' only with 'ability', which was thought to be unfit for this blank. The failure to make a final choice shows that P6 could not balance the weights of competing choices in terms of function-to-form mapping. The blank in Sentence 12 requires a modal verb which expresses epistemic judgment. As 会, 能 and 可以 can all be mapped to not only ability but also epistemic possibility, the use of them depends on the contexts. Unclear about this, participants may feel a lot of ambiguity and competition between them.

The above two examples reveal that most participants have not mastered the epistemic function of Chinese modal verbs very well and thus they may have problems in matching modal forms to modal meanings in the Epistemic Domain. However, competition between modal forms can happen in every conceptual domain of modality where ambiguity exists, as shown in Table 3 . In the process of competition and mapping, some participants succeeded in balancing the competing forms and eventually chose the most appropriate one, and some other participants failed to do so due to complete uncertainty. According to the think-aloud recording, a few of those who succeeded in function-to-form mapping are found to have resorted to their pragmatic awareness about how the modal verbs concerned are used in communication, for example, depending on the politeness principle or depending on the equal/unequal relationship between the speaker and the listener. That is to say, when two or more forms which are semantically and syntactically similar compete against each other, pragmatic criterion might be taken into consideration by some participants. From Table 1 it can be seen that the participants did the best in the Speech Act Domain, probably because this domain is directly related to language in daily communication, and speech acts are directly related to pragmatic principles.

Some other participants may resort to social context when feeling unsure between two competing forms. For example, when P2 hesitated between “会” and “要” for Sentence 14, he said: "I would try to think how my Chinese friends or other Chinese people would say this sentence and then decide which one is better." The influence of social context on language use will be discussed in the following section.

\section{Discussion}

In the above sections from 4.1-4.3, participants' performance in function-to-form mapping has been described and has been cognitively accounted for in terms of ambiguity and competition.

From Table 3 it can be seen that the Epistemic Domain is the domain in which the most ambiguities exist and accordingly the fewest participants made proper choices in this domain (as shown in Table 1). It implies that classroom instruction on the epistemic usage of modal verbs might need to be strengthened.

From this think-aloud study it can be observed that competition between modal verbs arose where participants perceived ambiguity between modal forms which express similar functions. Several pairs of confusing modal verbs found in this study have been presented in Table 3 and Table 4. Some of these pairs have been analyzed previously by $\mathrm{Hu}$ based on questionnaire study [10] and by Zhang based on HSK corpus [11]. The present study, based on the think-aloud real-time data from participants, has verified that “会/能” and “能/可以” are pairs of modal verbs which caused confusion among learners of Chinese. This indicates that it is important for teachers of Chinese to elaborate on the differences between the confusing modal verbs in each pair so as to reduce ambiguity between them. Both semantic ambiguities and syntactic ambiguities exist in the acquisition of modality and such ambiguities need to be identified and explicitly explained during classroom instruction [12].

Cognitive ambiguity between modal verbs and cognitive processing of modal tasks in terms of function-to-form mapping have both been observed from the present study. Apart from the cognitive aspect of learning, the influence of the social aspect on acquisition is also evident in the think-aloud report from the participants when they processed the modal task. As all the participants study or work in China, besides classroom instruction they have received in terms of Chinese learning, the influence of the social context on their acquisition of Chinese is worth noticing and worth discussing about.

According to Ellis, two types of learning can be distinguished: implicit and explicit [9]. For those who live in the environment of the target language, untutored acquisition happens when they are involved in communication outside the classroom. In this case, they may acquire the language implicitly. The result of implicit learning might be that learners have communicatively managed to know how to use the language - to choose appropriate forms to express particular functions - but they can't explain why. For example, P3 said in the think-aloud process for Sentence 20 after he made the most appropriate choice: "Sometimes you can't explain. I chose it by intuition. I remember what Chinese people say, without knowing the grammar rules. I don't know exactly how the language works". This seems to reveal the distinction between "explicit/declarative knowledge and implicit/procedural knowledge" [9]. Implicit knowledge is procedural, not declarative. That might be why P3 couldn't 
explain the reason why he chose what he chose. In the present think-aloud study, some other participants also intuitively chose the most appropriate modal forms for some given sentences without being engaged in much weighing process of different modal choices. They referred to it as "intuition". P6 who is an untutored learner said things like the following after having made the choice for Sentence 6, 7, 15 and 17: "I chose by intuition; I don't have to think, I heard it so many times; I never study grammar, I learn by myself; I don't know exactly why." It can be seen that when participants processed some of the modal sentences through their implicit knowledge there is less weighing and balancing in terms of function-to-form mapping.

Implicit knowledge comes from contact language learning, i.e., the communicatively oriented experiences, which is related to the social context. According to Block, learning is more than information processing, so there should be a social turn in SLA studies [13]. Through the present study which was done under the concept-oriented approach that investigates function-to-form mapping through tasks which emphasize communication, it is understood that studies on language learning need a socio-cognitive perspective, seeing acquisition as the product of both cognitive processing and social interaction. It is said that no theory can ignore the importance of the social context of learning [9], i.e., implicit learning through social interaction is important. But the effectiveness of explicit learning should not be ignored either, as it is pointed out that "there is evidence that learning though an explicit presentation of a (linguistic) rule can sometimes work more effectively than acquiring a rule implicitly" [4]. This indicates that both explicit learning and implicit learning are indispensable in Second Language Acquisition.

\section{Conclusion}

From this think-aloud study of modal use in terms of function-to-form mapping, it is found that:

1) Among the five Chinese modal verbs “会, 要, 能, 可以, 应该”, “能” is comparatively less used and less appropriately used by the participants to express the functions in all the three conceptual domains of modality, which indicates that more input and instruction about “能” needs to be provided to learners of Chinese so as to familiarize them with its use;

2) Meaning is essential in the task of function-to-form mapping and some participants were indeed aware of the equivalence of meaning in this mapping task, yet the think-aloud process of some participants reveals that they are not fully aware of the polysemous feature and multifunctionality principle of modal verbs. This indicates that more explicit presentation of modal meanings and modal rules needs to be given during classroom instruction. Palmer's idea of modality that all the meanings of modal verbs derive from the core meaning ("possibility/necessity") [14] is recommended for use by teachers of Chinese in their teaching design of polysemous and multifunctional modal verbs;
3) It can be observed from the think-aloud recording that competition arose in the participants' mind where they felt ambiguities between two modal forms which express similar functions. For example, 会/能 and 能/可以 are found to be two pairs of confusing modal verbs which baffled many of the participants. To ensure efficient use of modal verbs in communication, it is necessary for teachers to reduce ambiguity between modal forms so as to minimize the processing time in modal use;

4) There exist the most ambiguities in the Epistemic Domain of modal use, hence the participants failed to do well in using modal verbs for epistemic functions. As epistemic use of modal verbs is quite important in academic language $[15,16]$, it is suggested that function-to-form training in terms of epistemic modality needs to be strengthened during classroom instruction. In comparison, the participants did better in the Speech Act Domain, in which they seemed to perceive fewer ambiguities, probably because they have acquired implicit knowledge about modal forms for the function of speech acts, which they are more familiar with through real-life communication. From the recorded data of their think-aloud process, the influence of social context on their use of modal verbs is evident.

This think-aloud study aimed to investigate the cognitive process of function-to-form mapping of modal verbs, but at the same time it is found that it is hard to ignore the social aspect of language learning, as the participants in this study live in the environment of the target language and have access to real-life communication in the target language. As communication is the overriding concern of functionalists [3], it is suggested that future studies on modal verbs from the concept-oriented perspective focus more on the influence of social interaction on modal acquisition.

This study carries considerable pedagogical implications for modal acquisition, but its limitations need to be noted as well: as it is a case study, the results of this study are only descriptive, not inferential. This study investigated how modal functions in the three conceptual domains are expressed by the participants through function-to-form mapping, but it didn't study how the expression of modality (as a concept) changes over time, and it studied only modal verbs, not including other linguistic devices that can also express the concept of modality. Future studies on modal use from the concept-oriented perspective may investigate how learners' use of different modal devices changes over time so as to get an insight into not only modal use but also modal development.

\section{Acknowledgements}

This paper is the research results from the Humanities and Social Sciences Project (15YJA740017) which is funded by Ministry of Education of China. I'm grateful for its financial support on the study of modal acquisition and modal ambiguities. 


\section{References}

[1] Sweetser, E. (1990). From Etymology to Pragmatics: Metaphorical and Cultural Aspects of Semantic Structure. Cambridge: Cambridge University Press.

[2] Shen, J. X. (2003). Compound Sentences in Three Conceptual Domains: Acting, Knowing, and Uttering. Chinese Language, (3): 195-205.

[3] VanPatten, B. \& Williams, J. (2015). Theories of Second Language Acquisition: An Introduction ( $2^{\text {nd }}$ edition). New York: Routledge: 54-68.

[4] Ellis. R. (1999). The study of Second Language Acquisition. Shanghai: Shanghai Foreign Language Teaching Press: 360.

[5] Guo, C. J. (2015). Think-aloud Protocols in Foreign Language Teaching Research. Beijing: Foreign Language Teaching and Research Press: 6-10.

[6] Lai, P. (2016). A multiple-perspective study on English speaker's acquisition of Chinese modal verbs. Guangzhou: Sun Yat-sen University Press: 57.

[7] Coates, J. (1983). The semantics of the modal auxiliaries. London: Croom Helm: 16.

[8] Ely, C. (2002). Tolerance of ambiguity and the teaching of ESL In "Learning styles in the ESL/EFL classroom" (edited by Joy M. Reid). Beijing: Foreign Language Teaching and Research Press: 87-89.

[9] Ellis, R. (2015). Understanding Second Language Acquisition ( $2^{\text {nd }}$ edition). Oxford: Oxford University Press: 212-220.

[10] Hu, M. (2009). A Study on the Acquisition of Modal Verb "Can" (Neng) by Western Students. Master thesis of Beijing Language and Culture University, China: 31-32.

[11] Zhang, N. (2018). A Study on the Confusion Conditions of Chinese Modal Verbs among Foreign Learners. Master thesis of Shandong Normal University, China: 14, 18.

[12] Lai, P. (2020). Semantic and syntactic ambiguities in the acquisition of Chinese modal verbs: based on intralingual and interlingual differences. Linguistics and Literature Studies, 8 (4): 206-214.

[13] Block, D. (2012). The Social Turn in Second Language Acquisition. Beijing: World Publishing Corporation: 115.

[14] Palmer, F. R. (2007). Mood and modality ( $2^{\text {nd }}$ edition). Beijing: World Publisher Corporation: 89-99.

[15] Vold, E. T. (2006). Epistemic modality markers in research articles: A cross-linguistic and cross-disciplinary study. International Journal of Applied Linguistics, 16 (1): 61-87.

[16] Lai, P. (2021). A Correlative Study on Epistemic Modal Use and Tolerance of Ambiguity: Based on Functionalist Theories in Second Language Acquisition. International Journal of Language and Linguistics 9 (4): 169-179. 